\title{
QUALIVERDE: HISTÓRICO, PROJETOS E PRÓXIMOS PASSOS
}

\author{
QUALIVERDE: HISTORY, PROJECTS AND NEXT STEPS
}

\author{
Marcelo de Mattos Bezerra, Doutor em Design (PUC-Rio) \\ Alfredo Jefferson de Oliveira, Doutor em Eng. da Produção (PUC-Rio)
}

\section{Palavras Chave}

Sustentabilidade; Construção Sustentável; Legislação; Incentivos à Sustentabilidade

\section{Key Words}

Sustainability; Sustainable Construction; Building Legislation; Incentives for Sustainability

\section{RESUMO}

Este artigo expõe a qualificação Qualiverde lançada em 2012 pela Prefeitura da Cidade do Rio de Janeiro e complementa trabalho apresentado pelos mesmos autores no 5 SBDS - Simpósio de Design Sustentável - em 2015 no Rio de Janeiro. A qualificação para edifícios sustentáveis parte da legislação edilícia da cidade, incluindo novas exigências e estimulando a adoção de soluções sustentáveis. O Qualiverde pode ser obtido, porém os benefícios edilícios e fiscais até o momento (ago. 2016), ainda não foram aprovados pela Câmara de Vereadores. O artigo é composto por: breve histórico da elaboração da qualificação, seus participantes e estratégia para lançamento; principais pontos da qualificação com descrição dos temas envolvidos - Gestão da Água, Eficiência Energética e Desempenho Térmico, Projeto e Bonificações; projetos submetidos à qualificação; considerações do grupo de técnico sobre a qualificação e possíveis adequações.

\section{ABSTRACT}

This article discusses the Qualiverde certification launched in 2012 by the City Council of Rio de Janeiro and supplements the paper submitted by the same authors at the 5th SBDS - Sustainable Design Symposium - in 2015 in Rio de Janeiro. The certification for sustainable buildings is based on the city's building legislation, including new requirements and encouraging the adoption of sustainable solutions. Qualiverde can be obtained, however the construction and tax benefits have not yet been approved (Aug 2016) by the Chamber of Councilors. The article is comprised of: a brief history of the certification's preparation, its participants and a strategy for launch; the certification's main points with a description of the subjects involved - Water Management, Energy Efficiency, Thermal Performance, Design and Bonuses; projects submitted to certification; observations of the expert group on the certification and possible adjustments. 


\section{INTRODUÇÃO}

O desenvolvimento da Construção Sustentável tem sido incentivado em diversos países com antigos procedimentos e novas tecnologias agregadas para uma nova geração de edificações que respeitam o meio ambiente, otimizam uso de recursos e causam menos emissões (BEZERRA, 2013).

Para comprovação do nível de sustentabilidade em novas edificações e em projetos de renovação de construções existentes são adotados certificações e selos em cidades e países pelo mundo (BEZERRA, 2013).

Figura 01 - Mapa com algumas das principiais certificações pelo mundo, os adotados ou criados no Brasil

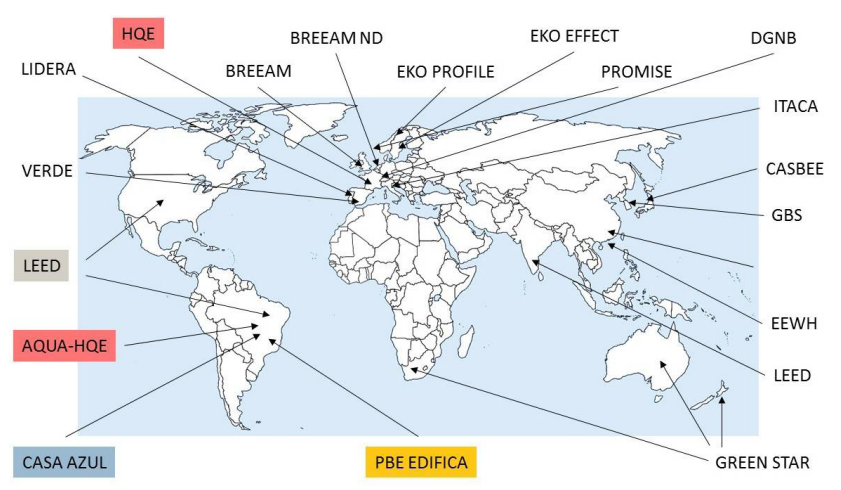

Fonte: BEZERRA; OLIVEIRA, 2015.

No Brasil as principais certificações, etiquetas e selos são (BEZERRA; OLIVEIRA, 2015):

- AQUA, atual Certificado HQE, na França, o Processo HQE - Haute Qualité Environnementale - e adaptado no Brasil pela Fundação Vanzolini da Politécnica da USP.

- LEED - Leadership in Energy and Environmental Design, criado pelo USGBC - United States Green Building Council.

- PBE Edifica - Brasil: Etiqueta de Eficiência Energética, parceria entre o Inmetro e a Eletrobrás, para edificações comerciais, de serviços e públicos e residenciais.

- Selo Casa Azul-Brasil:Desenvolvido pela Caixa Econômica Federal para empreendimentos financiados pelo banco.

Muitos itens incluídos em certificações derivam de legislações existentes em cidades e/ou países e tem na superação de exigências das mesmas atribuídas pontuações (BEZERRA, 2013; apud BEZERRA; OLIVEIRA, 2015).

Cada cidade tem sua legislação edilícia com especificidades de acordo com as prioridades e necessidades. Além dos parâmetros urbanísticos podem ser incorporadas ações para melhor gestão de recursos, conforto ambiental e eficiência energética.

No Reino Unido, por exemplo, há uma legislação nacional para edificações, mas cada cidade e, em muitos casos, os bairros, tem planos que se complementam, direcionando a inclusão da sustentabilidade focados nas características climáticas e de localização do projeto. Londres pode ser citado como referência com um plano completo e bem definido. No Reino Unido não há incentivos para os procedimentos exigidos (MARTINS, 2016).

Na cidade do Rio de Janeiro em 2012 foi lançada a qualificação Qualiverde - Qualificação para Construções Sustentáveis - para reconhecer a inclusão de soluções relacionadas a sustentabilidade com benefícios fiscais e edilícios para compensar a elevação de custos (BEZERRA; OLIVEIRA, 2015).

O presente texto complementa o trabalho apresentado e publicado no $5^{\circ}$ Simpósio de Design Sustentável (2015) e baseia-se em pesquisa bibliográfica e exploratória no tema, entrevistas com o grupo de trabalho responsável pelo Qualiverde, em especial do coordenador do mesmo, arquiteto Pedro Rolim.

Serão apresentados breve histórico e a estrutura da qualificação, projetos qualificados ou em processo de qualificação e análises de profissionais componentes do grupo de trabalho do Qualiverde.

\section{DESENVOLVIMENTO}

No ano de 2012 se realizou a Rio +20, evento que reuniu no Rio de Janeiro instituições e especialistas na área de sustentabilidade para revisão dos resultados da ECO92 e elaboração de novos compromissos relacionados ao meio ambiente (ONU, 2016).

Nesta ocasião a Prefeitura da cidade lançou a qualificação Qualiverde como ferramenta de incentivo à sustentabilidade e adoção de soluções sustentáveis para construções novas e existentes no município (BIAGINI, mai. 2016).

\subsection{Breve Histórico}

A qualificação foi elaborada entre o fim de 2010 e junho de 2012 (ROLIM, 2016) por equipe composta de profissionais das Secretarias de Urbanismo e de Meio Ambiente da prefeitura coordenada pela Secretaria de Urbanismo (BIAGINI, ago. 2016).

A intenção não foi gerar uma certificação, mas sim ferramenta para incentivo a inclusão da sustentabilidade em novos projetos (ROLIM, 2015). Foram estudadas diversas certificações para e definição do texto final, com destaque para o Selo Casa Azul, pelo seu sistema de pontos, e certificações como LEED e AQUA/HQE (ROLIM, 2016).

Ao longo da preparação da qualificação foram considerados o clima, as necessidades da cidade, itens da legislação edilícia existente, como a ventilação natural, insolação e a ampliação da taxa de permeabilidade (ROLIM, 2016).

Durante a elaboração da qualificação foi desenvolvido estudo em parceria com a ADEMI - Associação de 
Dirigentes de Empresas do Mercado Imobiliário - do Rio de Janeiro (ROLIM, 2015) para analisar a diferença entre o orçamento para construção de projetos sem e com a inclusão de itens previstos pela qualificação. Este estudo foi importante para identificar sobrecustos e balizar os benefícios a serem incluídos como incentivo (ROLIM, 2016).

A qualificação foi direcionada ao setor residencial pelo entendimento de que os edifícios corporativos já eram foco de ações do mercado. No processo de desenvolvimento foram realizadas apresentações a conselhos de meio ambiente e de urbanismo para consultas e confirmações (ROLIM, 2016).

A qualificação foi oficializada pelo Decreto n 35745, de 06 de junho de 2012. De acordo com Rolim (2016), o próprio nome não foi trabalhado em termos de marketing, sendo apenas uma abreviação das duas palavras envolvidas, qualificação e verde, esta indicando a sustentabilidade.

A qualificação é um sistema de pontuação de baixa complexidade. A aprovação é prioritária e segue trâmites de um projeto normal (ROLIM; apud BEZERRA; OLIVEIRA, 2015), mantidos os custos de um processo corrente de projeto (ROLIM, 2016). O Grupo de Trabalho do Qualiverde, específico para análise e aprovação de projetos, é coordenado desde o início pelo arquiteto Pedro Rolim.

Como incentivo para projetos qualificados foram propostas 2 (duas) leis (BIAGINI, ago. 2016):

1. Para benefícios edilícios - Projeto de Lei Complem. $\mathrm{n}^{\circ}$ 88/2012 (SMU/SMAC, 11 jun. 2012);

2. Para benefícios fiscais - Projeto de Lei Ordinário n¹.415/2012 (SMU/SMAC, 11 jun. 2012).

Para um empreendimento permanecer com os benefícios há a obrigatoriedade de manutenção das ações incluídas (ROLIM, 2015; apud BEZERRA; OLIVEIRA, 2015).

Os benefícios edilícios e fiscais ainda não foram aprovados pela Câmara de Vereadores do Município do Rio de Janeiro (BIAGINI, ago. 2016). Como 2016 será ano de eleições municipais, é provável que somente após as mesmas possa haver uma evolução.

Até o momento (ago. 2016), somente um projeto foi qualificado na categoria Qualiverde, com a concessão do Habite-se e processo concluído (BIAGINI, ago. 2016).

\subsection{Estrutura e Análises do Qualiverde}

São 2 (duas) as categorias da qualificação (SMU, 06 jun. 2012): Qualiverde: mínimo de 70 pontos; Qualiverde Total: para projetos que obtenham 100 pontos ou mais.

A qualificação se divide nos seguintes temas: Gestão da Água, Eficiência Energética e Desempenho Térmico, Projeto e Bonificações (BEZERRA; OLIVEIRA, 2015).
Serão descritos os itens para atendimento e pontuação total de cada um dos temas (SMU/SMAC, 05 dez. 2012) e na sequência comparativos entre os mesmos destacando diferenças de edifícios novos para existentes.

Tabela 01: Itens e Pontuações para Gestão da Água

\begin{tabular}{l|l|c}
\multicolumn{2}{l|}{ Gestão de Água } & P TS \\
\hline $\mathbf{1}$ & $\begin{array}{l}\text { Dispositivos economizadores - registros de vazão: } \\
\text { arejadores e registros reguladores nas torneiras }\end{array}$ & 2 \\
\hline 2 & $\begin{array}{l}\text { Dispositivos economizadores - descarga: } \\
\text { Descarga com mecanismo de duplo acionamento }\end{array}$ & $\mathbf{2}$ \\
\hline $\mathbf{3}$ & $\begin{array}{l}\text { Medidores individuais: Individualização dos } \\
\text { medidores de consumo de água nas edificações }\end{array}$ & $\mathbf{1}$ \\
\hline $\mathbf{4}$ & $\begin{array}{l}\text { Sistema reuso águas servidas: tratam ento, reserva } \\
\text { e distribuição para bacias sanitárias }\end{array}$ & $\mathbf{1}$ \\
\hline $\mathbf{5}$ & $\begin{array}{l}\text { Sistema reuso águas negras: Separador águas } \\
\text { cinzas e negras, tratamento, reserva e distribuição }\end{array}$ & $\mathbf{8}$ \\
\hline $\mathbf{6}$ & $\begin{array}{l}\text { Aproveitam ento de águas pluviais: captação, } \\
\text { reserva e distribuição para atividades espec ficas }\end{array}$ & $\mathbf{1}$ \\
\hline $\mathbf{7}$ & $\begin{array}{l}\text { Infiltração - pavimentação permeável: Em, pelo } \\
\text { menos, 40\% da área do passeio }\end{array}$ & $\mathbf{2}$ \\
\hline $\mathbf{8}$ & $\begin{array}{l}\text { Retardo e infiltração de águas pluviais: Construção } \\
\text { de reservatórios }\end{array}$ & $\mathbf{1}$ \\
\hline $\mathbf{9}$ & $\begin{array}{l}\text { Ampliação áreas permeáveis além do exigido por } \\
\text { lei: Acréscimo 10\% além do obrigatório ou 30\% }\end{array}$ & $\mathbf{5}$ \\
\hline Total Gestão de Água & $\mathbf{2 3}$ \\
\hline
\end{tabular}

Fonte: BEZERRA; OLIVEIRA, 2015

Dos nove itens do tema Gestão de Água os 3, 6, 8 e 9 derivam de exigências da legislação edilícia da cidade.

Tabela 02: Itens e Pontuações para Eficiência Energética e Desempenho Térmico

\begin{tabular}{|c|c|c|}
\hline \multicolumn{2}{|r|}{ Eficiência Energética e Desempenho Térmico } & PTS \\
\hline \multirow[t]{4}{*}{10} & $\begin{array}{l}\text { Aquecimento solar da água: Coletor solar, } \\
\text { reservatório térmico, aquecim. auxiliar e } \\
\text { acessórios: }\end{array}$ & \\
\hline & $30 \%$ de toda a demanda de água quente & 5 \\
\hline & $50 \%$ de toda a dem anda de água quente & 7 \\
\hline & $100 \%$ de toda a demanda de água quente & 10 \\
\hline \multirow[t]{3}{*}{11} & Iluminação artificial eficiente, previstos 2 cenários: & \\
\hline & $\begin{array}{l}\text { lluminação da circulação pavimentos tipo e } \\
\text { circulação vertical com lâm padas LED }\end{array}$ & 2 \\
\hline & lluminação de toda área comum com LED & 4 \\
\hline 12 & $\begin{array}{l}\text { lluminação natural eficiente: Em } 50 \% \text { áreas } \\
\text { comuns (circulaçoes nos pavimentos tipo) }\end{array}$ & 5 \\
\hline 13 & $\begin{array}{l}\text { Eficiência sistema de iluminação: Distribuição em } \\
\text { circuitos independ. e dispos. economizadores }\end{array}$ & 2 \\
\hline 14 & $\begin{array}{l}\text { Fontes altemativas de energia: lluminação de } \\
\text { áreas comuns com uso painéis solares }\end{array}$ & 5 \\
\hline \multicolumn{2}{|r|}{ Total (máx. pos.) Efic. Energ. e Desemp. Térmico } & 26 \\
\hline
\end{tabular}

Fonte: Elaborado pelos autores a partir de BEZERRA; OLIVEIRA, 2015.

Nenhum dos itens do tema Eficiência Energética e Desempenho Térmico compõe a legislação edilícia do município. Os itens 10 e 14 incentivam a adoção de fontes renováveis para aquecimento de água e iluminação e os demais referindo-se à iluminação de áreas comuns nos pavimentos, sendo que o item 10 possui 3 (três) níveis de atendimento. 
Tabela 03: Itens e Pontuações para Projeto

\begin{tabular}{|c|c|c|}
\hline \multicolumn{2}{|r|}{ Projeto } & \multirow{2}{*}{\begin{tabular}{|c|} 
PT S \\
5
\end{tabular}} \\
\hline 15 & $\begin{array}{l}\text { Telhados de cobertura ierde: Pavto năo uflizácel } \\
\text { (podendo } 50 \% \text { para painéis fotovoltáicos) }\end{array}$ & \\
\hline 16 & $\begin{array}{l}\text { Orientaçăo ao Sol e Ventos: Estudos de insolaçăo } \\
\text { com solupŏes }\end{array}$ & 5 \\
\hline 17 & $\begin{array}{l}\text { Afastamento das divisas: Mesmo que a legislaçăo } \\
\text { pemita o năo áastamento e embasamento }\end{array}$ & 2 \\
\hline 18 & $\begin{array}{l}\text { Vedações adequadas à zona bioclimática 8: } \\
\text { Adoçăo de redacóes externas leves refetoras }\end{array}$ & 1 \\
\hline 19 & $\begin{array}{l}\text { Uso de Materiais Sustentáceis: Adesivos, selantes } \\
\text { e tintas de baixa emissáo; madeiras certificadas }\end{array}$ & 3 \\
\hline \multirow[t]{3}{*}{20} & \multicolumn{2}{|l|}{$\begin{array}{l}\text { Conforto acústico: Adọ̧ăo de materiais que } \\
\text { propiciem protecắo acústica: }\end{array}$} \\
\hline & $\begin{array}{l}\text { Uso isolamento nas paredes e tratamento acústico } \\
\text { compartimentos que gerem desconforto }\end{array}$ & 2 \\
\hline & $\begin{array}{l}\text { Adoçåo de esquadrias externas com tratamento } \\
\text { acústico }\end{array}$ & 5 \\
\hline 21 & $\begin{array}{l}\text { Isolamento térmico: Nas áchadas (vol tadas para } \\
\text { norte e oeste de insolaçăo direta) pode combinar } \\
\text { ao item } 29 \text { e atençào a fachadas envidraçadas }\end{array}$ & 3 \\
\hline 22 & $\begin{array}{l}\text { Plano de Reduçăo de Impactos Ambientais no } \\
\text { canteiro de obras }\end{array}$ & 3 \\
\hline 23 & Reaproveitamento de residuos no canteiro de & 3 \\
\hline \multirow[t]{3}{*}{$\overline{24}$} & \multicolumn{2}{|l|}{ Implantaçăo de bicicletánios e estrutura de apoio: } \\
\hline & $\begin{array}{l}\text { Edifcaçóes com. e institucionais } 20 \% \text { a } 30 \% \text { das } \\
\text { lagas carros; residenciais } 50 \% \text { dos aptos }\end{array}$ & 1 \\
\hline & $\begin{array}{l}\text { Edifcaçŏes comerciais e institucionais } 30 \% \text { das } \\
\text { agas carros; em residenciais } 100 \% \text { dos aptos }\end{array}$ & 3 \\
\hline \multirow[t]{3}{*}{25} & \multicolumn{2}{|l|}{ Previsào compartimento coleta seletica de lixo: } \\
\hline & Espaco entilado de f́cil acesso, se no térreo & 1 \\
\hline & Espaco ventilado de ácil acesso, se nos pavtos & 2 \\
\hline 26 & $\begin{array}{l}\text { Plantio espécies veg. nativas: Para sombreamento } \\
\text { passeio esp. min. de } 6 \mathrm{~m} \text { ou para copa }\end{array}$ & 2 \\
\hline \multirow[t]{3}{*}{27} & \multicolumn{2}{|l|}{ Ventilaçăo natural de banheiros: } \\
\hline & $\begin{array}{l}\text { Janela voltada para exterior ou prisma do edício } \\
\text { em todos os banheiros (exceto lavabos) }\end{array}$ & 4 \\
\hline & $\begin{array}{l}\text { Janela vol tada para exterior ou prisma do edíficio } \\
\text { em } 50 \% \text { dos banheiros (exceto lavabos) }\end{array}$ & 2 \\
\hline 28 & $\begin{array}{l}\text { Adequaçăo condiçóes terreno: Manutençăo leget. } \\
\text { existente e reduçăo alteraçăo morologia }\end{array}$ & 2 \\
\hline 29 & $\begin{array}{l}\text { Sistema de fachadas: Sistema de proteçăo e } \\
\text { sombreamento de fachadas }\end{array}$ & 4 \\
\hline 30 & $\begin{array}{l}\text { Vagas para éculos elétricos: Previsăo } 5 \% \text { total } \\
\text { exigido pcom estrutura para recarga }\end{array}$ & 1 \\
\hline$\overline{31}$ & $\begin{array}{l}\text { Estruturas metálicas: Em substituiçăo ao concreto } \\
\text { convencional (pela reciclagem, pré-fabricaçăo, } \\
\text { orpanizaçăo canteiro de obras e leveza) }\end{array}$ & 8 \\
\hline \multicolumn{2}{|r|}{ Total Proje to } & 56 \\
\hline
\end{tabular}

Fonte: Elaborado pelos autores a partir de BEZERRA; OLIVEIRA, 2015.

No tema Projeto os itens 17 e 27 são variações de exigências da legislação edilícia.

Além dos temas relacionados à edificação há um que prevê bonificações. Importante realçar a diferença da pontuação total disponível para projetos de edifícios novos e para edifícios existentes, que totalizam 8 e 25 pontos respectivamente, desconsiderando o item V (Inovações Tecnológicas) (ver Tabela 04).

$\mathrm{O}$ item I compensa e reconhece os limitadores pelas precondições em projetos de renovação de edifícios existentes. O item II corresponde a legislação para novas edificações licenciadas, mas pontua inclusão em edificações existentes. O item III corresponde a item da legislação.

Abaixo a Tabela 05 apresenta o peso de cada um dos temas em quantidade de pontos para projetos de edifícios novos e existentes.
Tabela 04: Itens e Pontuações para Bonificações

\begin{tabular}{|c|c|c|}
\hline \multicolumn{2}{|c|}{ Bonificaçöes } & \multirow{2}{*}{$\begin{array}{c}\text { PTS } \\
15 \\
\end{array}$} \\
\hline $\mathrm{I}$ & Retrofit de construções existentes & \\
\hline II & $\begin{array}{l}\text { Hidrômetros individuais (medição individualizada) } \\
\text { em reformas ou retrofit }\end{array}$ & 2 \\
\hline III & Reservatório de retardo sem obrigatoriedade & 3 \\
\hline IV & Selos de certificação e orientação ambiental (*1) & 5 \\
\hline V & Inovações tecnológicas $\left({ }^{*} 2\right)$ & 1 \\
\hline & $\begin{array}{l}\text { I Bonificações, se m incluir Inova ções tecnológi } \\
\left({ }^{*} \text { 1) Notas: No caso do processo da certificação }\right. \\
\text { ainda estar em andamento deverá ser anexado o } \\
\text { registro de abertura do processo comprovando a } \\
\text { tramitação. Para o PBE Edifica exigida obtenção } \\
\text { do Nivel A para o edificio completo e a pontuação } \\
\text { a ser obtida com a apresentação de certificações } \\
\text { diversas não é cumulativa. } \\
\text { (*2) } 1 \text { PONTO por inovação. }\end{array}$ & 25 \\
\hline
\end{tabular}

Fonte: BEZERRA; OLIVEIRA, 2015

Tabela 05: Comparativos entre itens para Edifícios Novos e Existentes

\begin{tabular}{|c|c|c|c|c|c|}
\hline & 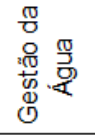 & 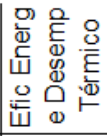 & $\frac{\stackrel{\circ}{\frac{\pi}{2}}}{\frac{2}{2}}$ & 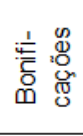 & 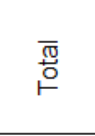 \\
\hline \multicolumn{6}{|l|}{ Novos: } \\
\hline Pontos & 23 & 26 & 56 & 8 & 113 \\
\hline$\%$ do total & $20.4 \%$ & $23.0 \%$ & $49.6 \%$ & $7.1 \%$ & $100.0 \%$ \\
\hline \multicolumn{6}{|l|}{ Existentes: } \\
\hline Pontos & 23 & 26 & 56 & 25 & 130 \\
\hline$\%$ do total & $17.7 \%$ & $20.0 \%$ & $43.1 \%$ & $19.2 \%$ & $100.0 \%$ \\
\hline
\end{tabular}

Fonte: Elaborado pelos autores a partir de BEZERRA; OLIVEIRA, 2015.

$\mathrm{Na}$ Tabela 05 verifica-se que o tema Projeto corresponde a $51,3 \%$ dos pontos possíveis para projetos novos e $44,6 \%$ para renovações. Não foram contabilizados os pontos por inovações. Para edifícios novos 117 pontos possíveis (BEZERRA; OLIVEIRA, 2015).

Como exemplo dos Benefícios Edilícios (em trâmite na CMRJ - Câmara do Município do Rio de Janeiro) podem ser citados: acréscimo de áreas de varandas e nas áreas do pavimento de cobertura - $25 \%$ a mais em relação ao permitido (ROLIM, 2015; apud BEZERRA; OLIVEIRA, 2015). Quadro 01: Benefícios fiscais concedidos

\begin{tabular}{l|c|c|c|c} 
& $\begin{array}{c}\text { IPTU antes } \\
\text { habite-se }\end{array}$ & $\begin{array}{c}\text { IPTU } \\
\text { após habite- } \\
\text { se }\end{array}$ & $\begin{array}{c}\text { ITBI } \\
1^{\text {a aquisição }}\end{array}$ & $\begin{array}{c}\text { ISS durante } \\
\text { a obra }\end{array}$ \\
\hline Qualiverde & $\begin{array}{c}50 \% \\
\text { Licencia- } \\
\text { mento ao } \\
\text { Habite-se }\end{array}$ & $10 \%$ & $50 \%$ & $1.50 \%$ \\
\hline $\begin{array}{l}\text { Qualiverde } \\
\text { Total }\end{array}$ & $\begin{array}{c}\text { Isento Li- } \\
\text { cenc. ao } \\
\text { Habite-se }\end{array}$ & $20 \%$ & ISENTO & $0.50 \%$ \\
\hline $\begin{array}{l}\text { Obser- } \\
\text { vações }\end{array}$ & $\begin{array}{c}\text { Prazo má- } \\
\text { ximo de 2 } \\
\text { exercícios }\end{array}$ & $\begin{array}{c}\text { Para unid. 3 } \\
\text { anos. Pode } \\
\text { ser cancel. }\end{array}$ & & $\begin{array}{c}\text { Alíquota } \\
\text { usual } \\
\text { durante obra } \\
3 \%\end{array}$
\end{tabular}

Fonte: BEZERRA; OLIVEIRA, 2015. 
Os Benefícios Fiscais (em trâmite na CMRJ) (SECRETARIA DE URBANISMO RJ, 2012; apud BEZERRA; OLIVEIRA, 2015) são os seguintes (Quadro 01):

No Quadro 01 fica evidente a diferença das reduções de taxas e impostos entre os níveis Qualiverde. No Qualiverde Total os descontos dobram ou triplicam (no caso do ISS) em comparação ao nível Qualiverde.

\subsection{Projetos qualiverde}

Até o momento foi qualificado um projeto (com Habite-se concedido) para um edifício comercial no nível Qualiverde com 70 pontos. Além deste projeto, 3 (três) outros estão aguardando o habite-se ou em processo de aprovação, 2 (dois) em fase inicial de consultas e outros retirados antes do início do processo (ROLIM, 2016).

O grupo de trabalho forneceu dados sobre os 4 (quatro) projetos com processos mais avançados de qualificação (subcapítulos 2.3.1. e 2.3.2.). A partir destes dados foram elaborados comparativos (subcapítulo 2.3.4.) dos pontos obtidos e possíveis para o Qualiverde de cada um dos projetos.

\subsubsection{Projeto qualificado com habite-se concedido}

Trata-se de um edifício comercial que foi renovado e obteve 72 pontos. Durante o processo houve ajustes como a retirada dos hidrômetros individuais, devido ao alto custo. Dentro do edifício há um interessante sistema de tratamento de águas negras. $\mathrm{O}$ projeto foi elaborado por escritório de arquitetura carioca que tem experiência em projetos com inclusão de soluções de sustentabilidade. Para este projeto não houve a inclusão de pontuação pela certificação do empreendimento, item IV do tema Bonificações (ROLIM, 2016).

$\mathrm{Na}$ Tabela 06 pode se constatar o peso do tema Bonificações no total do projeto com o mesmo correspondendo a $27,8 \%$ dos 72 pontos obtidos.

Tabela 06: Comparativos entre itens obtidos e possíveis projeto de renovação de edifício comercial

\begin{tabular}{|c|c|c|c|c|c|}
\hline & 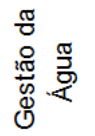 & 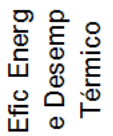 & $\frac{}{\frac{0}{0}}$ & 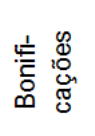 & $\begin{array}{l}\bar{\pi} \\
\text { 음 }\end{array}$ \\
\hline pts obtidos & 13 & 18 & 21 & 20 & 72 \\
\hline$\%$ do total & $18.1 \%$ & $25.0 \%$ & $29.2 \%$ & $27.8 \%$ & \\
\hline pts possíveis & 23 & 28 & 58 & 25 & 134 \\
\hline$\%$ entre pts $\left(^{*}\right)$ & $56.5 \%$ & $64.3 \%$ & $36.2 \%$ & $80.0 \%$ & $53.7 \%$ \\
\hline
\end{tabular}

(*) \% entre os pts obtidos e os pts possíveis.

Fonte: Elaborado pelos autores com base dados fornecidos.

\subsubsection{Projetos em qualificação ainda sem habite-se}

São 3 (três) os projetos em processo de qualificação, sendo o projeto B de renovação (ROLIM, 2016):

\section{A. Centro de Treinamento: Obteve 85 pontos.}

Tabela 07: Comparativos entre itens obtidos e possíveis projeto de centro de treinamento

\begin{tabular}{|c|c|c|c|c|c|}
\hline & $\begin{array}{l}\frac{\pi}{0} \\
0 \\
\frac{\pi}{00} \\
\frac{\pi}{0} \\
0 \\
0 \\
0\end{array}$ & 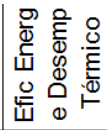 & $\frac{\circ}{\frac{0}{0}}$ & 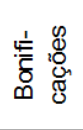 & 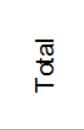 \\
\hline pts obtidos & 23 & 28 & 34 & 0 & 85 \\
\hline$\%$ do total & $27.1 \%$ & $32.9 \%$ & $40.0 \%$ & $0.0 \%$ & \\
\hline pts possíveis & 23 & 28 & 58 & 8 & 117 \\
\hline$\%$ entre pts $\left({ }^{*}\right)$ & $100.0 \%$ & $100.0 \%$ & $58.6 \%$ & $0.0 \%$ & $72.6 \%$ \\
\hline
\end{tabular}

Fonte: Elaborado pelos autores com base dados fornecidos

O projeto atingiu $100 \%$ nos temas Gestão da Água e Eficiência Energética e Desempenho Térmico com 85 pontos sem itens de Bonificações.

B. Restaurante: Atingiu 70 pontos.

Tabela 08: Comparativos entre itens obtidos e possíveis projeto de renovação de restaurante

\begin{tabular}{|c|c|c|c|c|c|}
\hline & 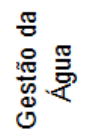 & 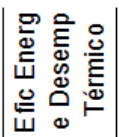 & $\frac{}{\frac{0}{2}}$ & 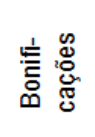 & 픙 \\
\hline pts obtidos & 8 & 28 & 16 & 18 & 70 \\
\hline$\%$ do total & $11.4 \%$ & $40.0 \%$ & $22.9 \%$ & $25.7 \%$ & \\
\hline pts possiveis & 23 & 28 & 58 & 25 & 134 \\
\hline$\%$ entre pts $\left({ }^{*}\right)$ & $34.8 \%$ & $100.0 \%$ & $27.6 \%$ & $72.0 \%$ & $52.2 \%$ \\
\hline
\end{tabular}

$\left({ }^{*}\right) \%$ entre os pts obtidos e os pts possíveis.

Fonte: Elaborado pelos autores com base dados fornecidos.

Orestaurante obteve $100 \%$ no tema Eficiência Energética e Desempenho Térmico, 72\% no tema Bonificações e baixa pontuação nos temas Gestão da Água e Projeto.

C. Residência Unifamiliar: É uma residência de alto padrão (BIAGINI, ago. 2016) concluindo o licenciamento. Este projeto apresentou memorial com 79 pontos, sendo concedidos 70 pontos. Durante a obra os pontos retirados serão trabalhados para serem reincorporados.

Tabela 09: Comparativos entre itens obtidos e possíveis projeto residência unifamiliar

\begin{tabular}{|c|c|c|c|c|c|}
\hline & 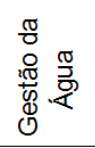 & 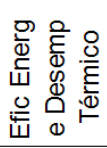 & $\frac{\frac{0}{0}}{\frac{0}{0}}$ & 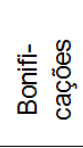 & 要 \\
\hline pts obtidos & 12 & 16 & 42 & 0 & 70 \\
\hline$\%$ do total & $17.1 \%$ & $22.9 \%$ & $60.0 \%$ & $0.0 \%$ & \\
\hline pts possiveis & 23 & 28 & 58 & 8 & 117 \\
\hline$\%$ entre pts $\left(^{*}\right)$ & $52.2 \%$ & $57.1 \%$ & $72.4 \%$ & $0.0 \%$ & $59.8 \%$ \\
\hline
\end{tabular}

Fonte: Elaborado pelos autores com base dados fornecidos.

Como demonstrado na Tabela 09, o tema Projeto obteve $72,4 \%$ dos pontos possíveis e $60 \%$ do total para a qualificação.

\subsubsection{Projetos em análise para qualificação}

2 (dois) projetos estão preparando memoriais para submissão (ROLIM, 2016): uma instituição de ensino e um edifício comercial. 


\subsubsection{ComparaçãoentreProjetosem Qualificação}

Os projetos de renovação foram os que obtiveram pontos no tema Bonificações, até pelos 15 pontos fornecidos a esta categoria de projeto.

Dos 4 (quatro) projetos o restaurante (renovação) e o centro de treinamento (nova construção) obtiveram $100 \%$ dos pontos possíveis em dois dos temas, enquanto os projetos de novas construções não computaram em Bonificações.

Quanto ao total de pontos, o projeto para o centro de treinamento foi o de pontuação mais elevada, com $40 \%$ no tema Projeto e nenhum ponto no tema Bonificações. Essa baixa pontuação nesses últimos temas evidencia o potencial para obtenção do Qualiverde Total.

\subsubsection{Projetos que não avançaram na qualificação}

Foram citados alguns multifamiliares que não prosseguiram e sem informações precisas dos motivos de desistência. Houve um projeto que, sendo uma combinação de nova construção e de renovação, mas que pela ausência, até o momento, de ponderação entre pontuações das duas modalidades de projeto, não avançou (ROLIM, 2016).

\subsection{Experiências e próximos passos do grupo de trabalho}

Neste subcapítulo serão apresentados principais pontos do resultado de entrevistas concedidas aos autores pela arquiteta Thais Garlet Biagini do Grupo de Trabalho em 19 de agosto de 2016 e pelo coordenador do Grupo de Trabalho do Qualiverde da Secretaria de Urbanismo, arquiteto Pedro Rolim, em 25 de agosto de 2016.

Rolim (2016) pontua inicialmente que, não sendo o Qualiverde "um fim, mas um meio" surpreendeu a procura pela qualificação, pois a expectativa seria de que somente com as leis de benefícios aprovadas a qualificação interessaria ao setor da construção na cidade.

Biagini (ago. 2016) entende que os empreendimentos multifamiliares que efetivaram consultas não avançaram na qualificação pela ausência dos benefícios.

Para Rolim (2016) é importante ter o grupo de trabaIho para um debate permanente de cada ação, o que tem permitido acompanhar a evolução e as necessidades e oportunidades de ajustes. Esse acompanhamento enriquecido pelas consultas e comentários de profissionais responsáveis pelos projetos apresentados.

Rolim (2016) destaca alguns dos ajustes após os 4 (quatro) anos de experiência:

1. O aquecimento solar de água não ser relevante em edifícios corporativos.
2.O fato das certificações para construções sustentáveis já serem uma exigêncwia para edifícios corporativos, principalmente quando do envolvimento de empresas estrangeiras.

3. Sugestões recebidas para pontuação quando da adoção de estrutura pré-moldada de concreto.

4. Quando de renovações (retrofits) parciais em projetos, combinação de nova construção e renovação de parte do projeto em aprovação, sendo necessária uma proporção da pontuação total possível (item I do tema Bonificações e comentado no subcapítulo 2.3.5.).

5. Adoção de pontuações intermediárias quando da inclusão parcial de telhados verdes.

6. Divisão entre as tipologias residenciais e comerciais.

Especificamente sobre os telhados verdes Biagini (ago. 2016) aponta que a principal discussão refere-se ao uso da laje, o que caracteriza o mesmo como mais um pavimento. Biagini entende também que as adoções de energia solar e de medição individualizada de água deverão ser incentivadas.

Outro aspecto para Rolim (2016) que favorece a evolução do projeto é que durante a obra há abertura para que sejam desenvolvidos ajustes com a exclusão ou inclusão de itens inicialmente previstos ou não.

Para Biagini (ago. 2016) é um aspecto positivo para os projetos que objetivem a qualificação a liberdade de opções de escolha dos temas e respectivos itens.

Rolim (2016) considera que a dificuldade para se obter os 100 pontos para o Qualiverde Total está implícita no processo, pois um empreendimento que realmente almeje a sustentabilidade atingirá este patamar de pontos. Um fato que evidencia esse potencial é de diversos projetos submetidos apresentaram boas pontuações e com um maior esforço, talvez incluídos com a compensação dos benefícios fiscais ainda não aprovados, superariam o mínimo exigido.

Biagini (ago. 2016) esclarece que o Qualiverde já está em vigor por decreto assinado pelo Prefeito. No entanto os projetos de leis de benefícios, por preverem alterações de normas construtivas e mudanças fiscais, tramitam obrigatoriamente pela Câmara de Vereadores.

Rolim (2016) conclui que não há nenhuma garantia que projetos em processo de aprovação ou já qualificados recebam os benefícios fiscais ainda em trâmite na Câmara de Vereadores.

\section{CONCLUSÃO}

O papel do poder público deve ser o de regulador e incentivador de melhores práticas. No Reino Unido existem as leis e orientações nacionais, municipais e até de bairros direcionando para sustentabilidade. A evolução da legislação, incorporando componentes e ações de 
sustentabilidade, é um passo fundamental para a melhor gestão de recursos e melhoria na qualidade de vida de habitantes de uma cidade. Trata-se de iniciativa em diversos países e aspecto chave para inclusão da sustentabilidade.

O Qualiverde agregar a uma legislação edilícia a sustentabilidade gerando benefícios para empreendimentos é passo importante. Cabe realçar que, mesmo sem os incentivos, projetos buscaram a qualificação. No cenário de aprovação das leis de benefícios, mesmo sem a confirmação dos ganhos para os respectivos projetos, esses empreendedores e equipes, terão a experiência na adoção da qualificação.

A manutenção do grupo de trabalho do Qualiverde, pela continuidade do processo, desde a elaboração e o aprendizado na submissão de diferentes projetos, contribui para o processo e evolução.

O foco inicial, quando da elaboração da qualificação, era a tipologia residencial multifamiliar, houve várias consultas para empreendimentos, porém, sem evolução, sendo provável que a não adesão de projetos de empreendimentos residenciais pela ausência dos benefícios.

A simplicidade da qualificação é um ponto positivo. A evolução pretendida, com divisão por tipologias, por exemplo residencial e comercial, objetivo de uma das mudanças planejadas pelo grupo de trabalho, será importante para orientar melhores práticas específicas de cada tipologia.

A relativa dificuldade para obtenção do Qualiverde Total é correta e direciona projetos para o melhor nível.

A adoção em larga escala da qualificação deverá ocorrer com a aprovação das leis de benefícios, sendo após esta aprovação possível avaliar a reação do mercado a primeira versão do Qualiverde e respectivos incentivos.

A flexibilidade para adequações de projetos durante a obra, pelas variáveis financeiras e tecnológicas, é um facilitador para tomadores de decisão de projetos.

O item II do tema Bonificações relacionado à medição individualizada deverá ser analisado, pois o impacto desta ação, pelas obras necessárias para implantação em edifícios existentes, poderia corresponder a uma maior pontuação.

Em próximas pesquisas planejamos ouvir atores do setor da construção no Rio de Janeiro quanto a expectativas e motivos para qualificação ou não pelo Qualiverde de seus empreendimentos e projetos; assim como ampliar o escopo das comparações adicionando outras experiências semelhantes ao Qualiverde desenvolvidas por órgãos públicos e prefeituras em cidades brasileiras e do exterior.

\section{REFERÊNCIAS}

BEZERRA, M. M.. 2013. Renovação da Quadra Urbana para a Sustentabilidade: Desafios e Soluções. Rio de
Janeiro: Tese de Doutorado. Departamento de Artes \& Design, Pontifícia Universidade Católica do Rio de Janeiro.

BEZERRA M. M.; OLIVEIRA A. J.. QUALIFICAÇÃO QUALIVERDE, A Legislação para Edifícios Sustentáveis do Rio de Janeiro e Análise Comparativa com Certificações. 50 Simpósio de Design Sustentável. PUCRio: Rio de Janeiro, 2015.

BIAGINI, Thais Garlet. Palestra sobre Qualiverde no Curso Sustentabilidade no Projeto da PUC-Rio em 31 mai. 2016.

BIAGINI, Thais Garlet. Entrevista: 19 ago. 2016.

MARTINS, Lilian. Conversa por telefone: ago. 2016.

ONU. Disponível em: <http://www.onu.org.br/ rio20/tema/rio20/>. Acesso em: 4 ago. 2016.

PREFEITURADACIDADEDORIODEJANEIRO.SECRETARIA DE URBANISMO. RESOLUÇÃO CONJUNTA SMU/SMAC N.॰ 02 DE 05 DE DEZEMBRO DE 2012: 05 dez. 2012.

PREFEITURADACIDADEDORIODEJANEIRO.SECRETARIA DE URBANISMO. RESOLUÇÃO CONJUNTA SMU/SMAC N.० 03 DE 05 DE DEZEMBRO DE 2012: 05 dez. 2012.

PREFEITURADACIDADEDORIODEJANEIRO.SECRETARIA DE URBANISMO. Decreto n` 35745: 06 jun. 2012.

PREFEITURA DA CIDADE DO RIO DE JANEIRO. SMU/ SMAC. Benefícios Edilícios PLC n 88/2012: 11 jun. 2012.

ROLIM, Pedro. Palestra sobre Qualiverde no Curso Sustentabilidade no Projeto da PUC-Rio em 16 jun. 2015.

ROLIM, Pedro. Entrevista: 23 e 25 ago. 2016. 